\title{
NIST Calibration of a Neutron Spectrometer ROSPEC
}

\begin{tabular}{lll}
\hline Volume 111 & Number 6 & November-December 2006
\end{tabular}

\section{Craig Heimbach}

National Institute of Standards and Technology,

Gaithersburg, MD 20899

craig.heimbach@nist.gov

\begin{abstract}
A neutron spectrometer was acquired for use in the measurement of National Institute of Standards and Technology neutron fields. The spectrometer included options for the measurement of low and high energy neutrons, for a total measurement range from $0.01 \mathrm{eV}$ up to $17 \mathrm{MeV}$. The spectrometer was evaluated in calibration fields and was used to determine the neutron spectrum of an Americium-Beryllium neutron source. The calibration fields used included bare and moderated ${ }^{252} \mathrm{Cf}$, monoenergetic neutron fields of $2.5 \mathrm{MeV}$ and $14 \mathrm{MeV}$, and a thermal-neutron beam. Using the calibration values determined in this exercise, the spectrometer gives a good approximation of the neutron spectrum,
\end{abstract}

\author{
and excellent values for neutron fluence, \\ for all NIST calibration fields. The \\ spectrometer also measured an \\ Americium-Beryllium neutron field \\ in a NIST exposure facility and \\ determined the field quite well. The \\ spectrometer measured scattering effects \\ in neutron spectra which previously could \\ be determined only by calculation or \\ integral measurements.
}

Key words: calibration; neutron; NIST; ROSPEC; spectroscopy.

Accepted: December 14, 2005

Available online: http://www.nist.gov/jres

\section{Introduction}

A Bubble Technology Industries (BTI) Rotating Spectrometer ${ }^{1}$ (ROSPEC) Ref. [1], was purchased by the National Institute of Standards and Technology (NIST) for use in applications supporting the Department of Homeland Security (DHS). NIST applications include the validation of the spectra of calibration sources and an evaluation of whether a neutron spectrometer could distinguish, through the measurement of neutron spectra, potential threat sources from innocuous sources.

ROSPEC has the unique ability to measure neutron spectra from $0.01 \mathrm{eV}$ to $17 \mathrm{MeV}$ with the spectrum above $50 \mathrm{keV}$ having resolution of $10 \%$ to $15 \%$. Currently, any neutron source of interest to Homeland Security will fall within this energy range.

Various configurations of ROSPEC exist. The configuration acquired by NIST includes seven detectors.

\footnotetext{
${ }^{1}$ Certain commercial equipment, instruments, or materials are identified in this paper to foster understanding. Such identification does not imply recommendation or endorsement by the National Institute of Standards and Technology, nor does it imply that the materials or equipment identified are necessarily the best available for the purpose.
}

There are two ${ }^{3} \mathrm{He}$ detectors, which determine the neutron spectrum from $0.01 \mathrm{eV}$ to $50 \mathrm{keV}$. This part of the spectrum is given in three groups, $0.01 \mathrm{eV}$ to $1 \mathrm{eV}$, $1 \mathrm{eV}$ to $10 \mathrm{keV}$, and $10 \mathrm{keV}$ to $50 \mathrm{keV}$. There are four gas-filled proton-recoil proportional counters which measure the spectrum from $50 \mathrm{keV}$ to $4.5 \mathrm{MeV}$. There is a plastic scintillator proton-recoil detector which measures the spectrum from $4 \mathrm{MeV}$ to $17 \mathrm{MeV}$. The energy spans of the various detectors overlap, providing some redundancy and consistency checks for the various detectors.

\section{Description of Detector System}

Currently, ROSPEC comes in three variants. The base system consists of four gas-filled proton recoil detectors which rotate about a common axis. Each detector is optimized to cover a particular energy range while being able to reject gamma rays because of pulse height. The total energy covered by the base system is $50 \mathrm{keV}$ to $5 \mathrm{MeV}$.

The base system is supplemented by two options. One is a set of paired bare/boron-covered ${ }^{3} \mathrm{He}$ detectors, which has sensitivity to neutrons down to thermal 
neutron energy. The other is a Simple Scintillation Spectrometer (SSS), several small plastic scintillators coupled to a photomultiplier tube, sensitive up to $17 \mathrm{MeV}$. The ${ }^{3} \mathrm{He}$ detectors are integrated into the base ROSPEC, while the SSS comes as a separate package. NIST purchased both options to be able to measure all neutron fields of interest to DHS.

Figure 1 shows the NIST system with its cover removed. The detectors are listed in Table 1. The largest detector, SP6, is the sphere on the right side of the picture. The boron-covered ${ }^{3} \mathrm{He}$ is the black sphere in the picture. The bare ${ }^{3} \mathrm{He}$ is mounted opposite the boron-covered detector to minimize interference with the opposite detector. In the picture it is behind the SP6.

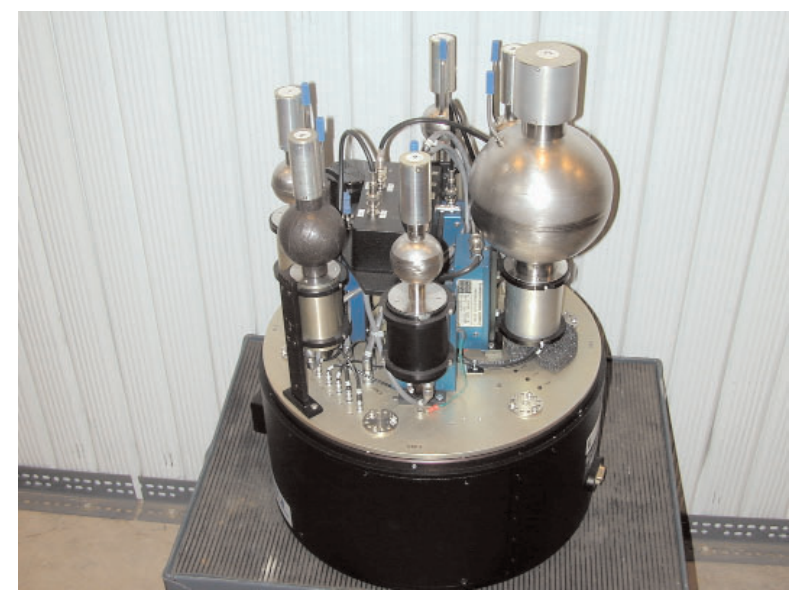

Fig. 1. Base ROSPEC with six proportional counters.
Figure 2 shows ROSPEC with its normal protective cover. Figure 3 shows the SSS.

In operation, the ROSPEC detectors rotate horizontally about an axis through the center of the cylinder at approximately 4 revolutions per minute. This averages out local variations in the neutron field. All of the ROSPEC electronics are located within the cylinder. It is connected to a control laptop computer through a $30 \mathrm{~m}$ long cable. The size of the package is $41 \mathrm{~cm}$ diameter by $60.5 \mathrm{~cm}$ high, with a mass of about $23 \mathrm{~kg}$.

The SSS consists of a detector and a control computer. The detector mass is approximately $3 \mathrm{~kg}$, with an overall length of $28 \mathrm{~cm}$. The control computer is an Atari portfolio which is connected to the detector with a $1.2 \mathrm{~m}$ long cable.

The neutron spectra must be analyzed, or unfolded, from the measured data. The ROSPEC data may be unfolded directly on the control computer. The SSS data must be downloaded through a parallel port on the Atari to the ROSPEC control computer for analysis. The provided software combines the ROSPEC and SSS data to derive a neutron spectrum. The unfolding above $50 \mathrm{keV}$ is based on the SPEC4 code [2], which is a spectrum stripping code. The response at any energy is corrected for response to higher-energy neutrons by stripping off their effects. Derivatives of the data and response functions are used to avoid accumulation of errors. The spectrum below $50 \mathrm{keV}$ is obtained with a three-energy-group fit to the bare and boron-covered ${ }^{3} \mathrm{He}$ data, joined to the spectrum from the higher energy detectors.

Table 1. ROSPEC detector characteristics

\begin{tabular}{|c|c|c|c|c|}
\hline Detector & Radius $(\mathrm{cm})$ & Fill Gas & Pressure $(\mathrm{kPa})$ & Energy Range \\
\hline${ }^{3} \mathrm{He}$ (bare) & 2.54 & ${ }^{3} \mathrm{He} / \mathrm{Kr}$ & 83 & $0.01 \mathrm{eV}-1 \mathrm{eV}$ \\
\hline${ }^{3} \mathrm{He}$ (boron) & 2.54 & ${ }^{3} \mathrm{He} / \mathrm{Kr}$ & 216 & $1 \mathrm{eV}-0.05 \mathrm{MeV}$ \\
\hline SP2-1 & 2.54 & H2 & 76 & $0.05 \mathrm{MeV}-0.25 \mathrm{MeV}$ \\
\hline SP2-4 & 2.54 & $\mathrm{H} 2$ & 400 & $0.15 \mathrm{MeV}-0.75 \mathrm{MeV}$ \\
\hline SP2-10 & 2.54 & $\mathrm{H} 2$ & 1000 & $0.4 \mathrm{MeV}-1.5 \mathrm{MeV}$ \\
\hline SP6 & 7.62 & $\mathrm{CH}_{4} / \mathrm{Ar}$ & 500 & $1.2 \mathrm{MeV}-5.0 \mathrm{MeV}$ \\
\hline SSS & $2.8 \mathrm{~cm}$ radius & N/A & N/A & $4 \mathrm{MeV}-16.6 \mathrm{MeV}$ \\
\hline
\end{tabular}




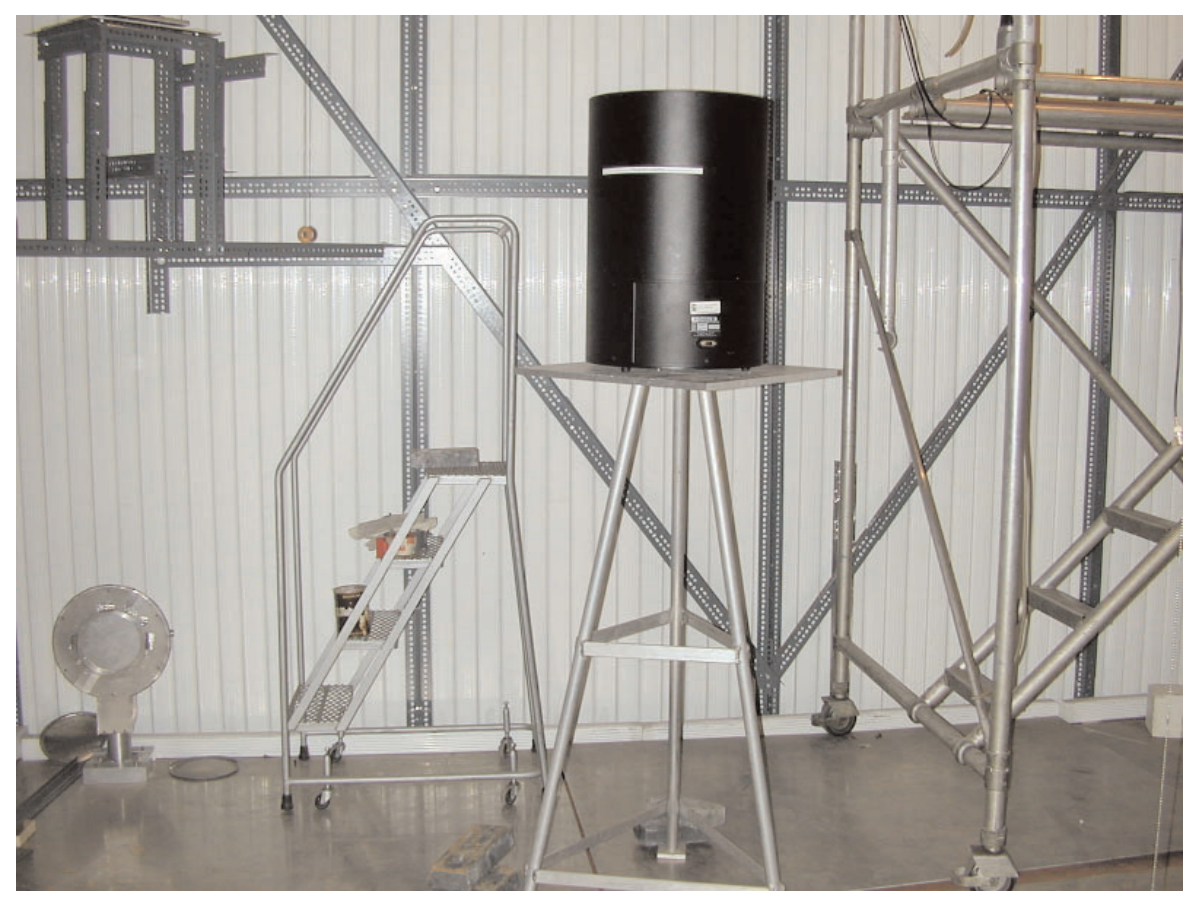

Fig. 2. ROSPEC with cover on

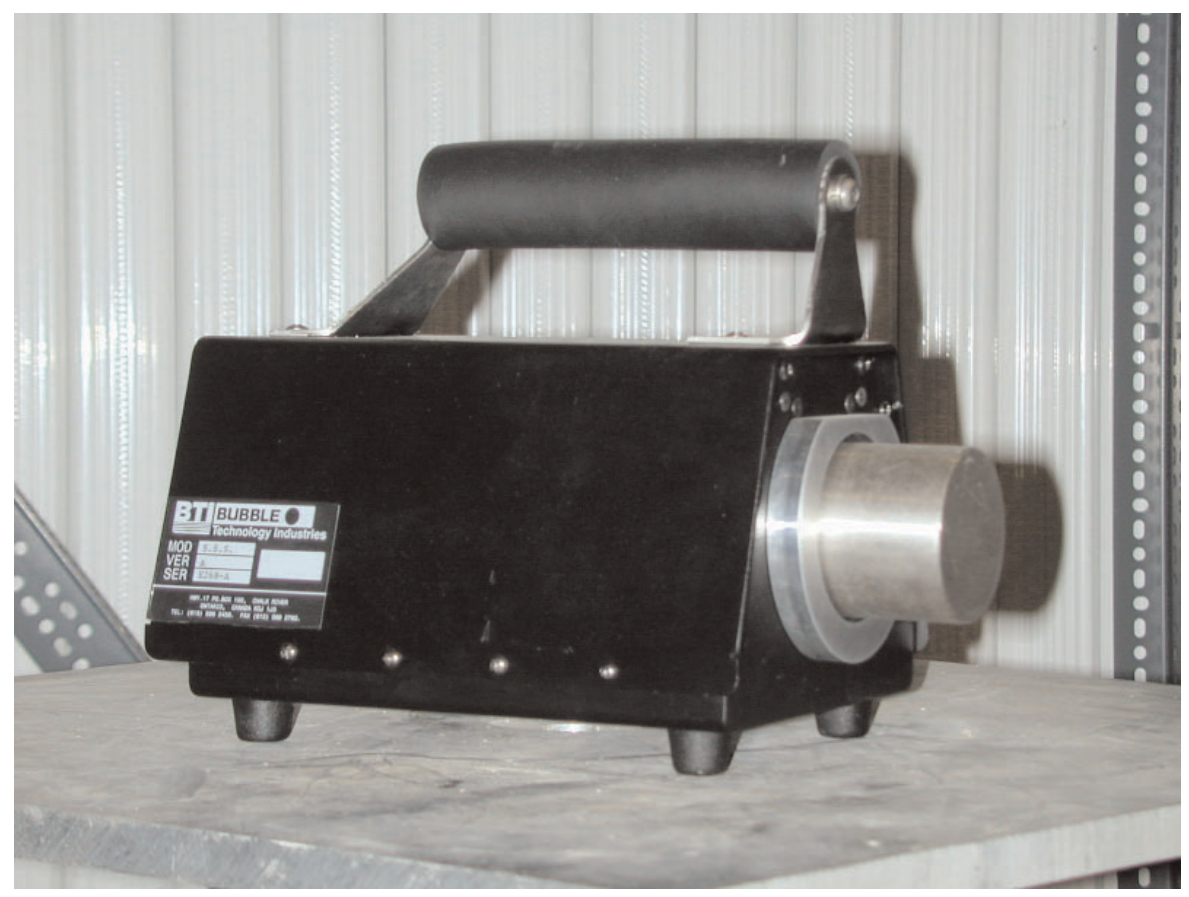

Fig. 3. Simple Scintillator Spectrometer (SSS) detector. 


\section{Calibration Fields}

NIST has several calibration fields useful for validating the performance of ROSPEC. These include bare [3] and heavy-water $\left(\mathrm{D}_{2} \mathrm{O}\right)$ moderated ${ }^{252} \mathrm{Cf}$ sources $[4,5]$, a thermal-neutron beam, and $2.5 \mathrm{MeV}$ and $14 \mathrm{MeV}$ sources. The $2.5 \mathrm{MeV}$ and $14 \mathrm{MeV}$ sources are of known energy, but NIST is still calibrating their output intensity. These sources span the energy range of ROSPEC.

Two of these sources, the bare and moderated ${ }^{252} \mathrm{Cf}$, are used in the NIST low-scatter facility [6]. This is a room, $11 \mathrm{~m} \times 11.6 \mathrm{~m} \times 9.6 \mathrm{~m}$ high, separate into two sections by an aluminum mezzanine. The lower section is below grade, with concrete floor and concrete walls approximately $4.6 \mathrm{~m}$ high. When used for calibration, either the bare or moderated source is exposed in the lower section, approximately centered in all directions. The upper section has aluminum walls and ceiling. These sources are international standard sources.

Although these two sources are well-characterized at all neutron energies, the actual spectrum is not normally used for calibration. NIST practice is to correct for the effects of room scattering in any measurement so the reported results are appropriate for pure (unscattered) fields. For calibration of spectra, the actual spectrum at $100 \mathrm{~cm}$ (center-to-center) was used for comparison. Monte Carlo N-Particle (MCNP) [7] calculations were performed to obtain the theoretical spectra. These calculations included air, the concrete floor and walls, and the aluminum mezzanine and upper section aluminum walls.

The NIST thermal neutron calibration facility was used to check the thermal-neutron calibration. This facility consists of a collimated beam with a line-ofsight view of a graphite moderator alongside the core of NIST research reactor. The graphite moderator is outside the heavy-water moderator of the reactor and shielded by bismuth. Thermal-neutron fluence calibration was provided with a ${ }^{239} \mathrm{Pu}$ fission chamber with an overall accuracy of $5 \%$.

The remaining calibration sources, the $2.5 \mathrm{MeV}$ and $14 \mathrm{MeV}$ neutron generators are located in the NIST Californium Neutron Irradiation Facility (CNIF). The CNIF consists of a room within a room. The outer concrete walls enclose a $10 \mathrm{~m} \times 15 \mathrm{~m} \times 6.2 \mathrm{~m}$ high room. Calibrations are performed within $6.3 \mathrm{~cm}$ thick shell of anhydrous borax, which reduces neutron room return from the concrete. The interior dimensions of the shell are $5.2 \mathrm{~m} \times 5.2 \mathrm{~m} \times 5.9 \mathrm{~m}$ high. The neutron generators provide neutrons of known energy, but are not yet calibrated for intensity.

\section{Calibration Measurements}

This memo records the performance of ROSPEC in the various fields. Previously, NIST had calibrated a version of ROSPEC containing only the proton recoil detectors, with good results [8]. Other calibration and intercomparison results are listed in Refs. $[9,10,11]$. Two sets of ROSPEC calibration constants will be used to compare measurements with calibration values, one set supplied by the manufacturer and another set derived in the course of these measurements. The two sets of constants differ only in their efficiencies for detecting low-energy neutrons, i.e., only for the bare and boron-covered ${ }^{3} \mathrm{He}$ detectors.

The first measurements were in the bare and heavywater moderated ${ }^{252} \mathrm{Cf}$ driven neutron fields. The best estimates of the spectra for the two fields were compared directly to measurements. These estimates were MCNP calculations of the spectrum which included scattering from air, walls, floor, and ceiling.

Figure 4 shows a comparison of the bare ${ }^{252} \mathrm{Cf}$ versus measurement, and Fig. 5 shows a comparison of the heavy-water moderated ${ }^{252} \mathrm{Cf}$ versus measurement. Above $100 \mathrm{keV}$, the agreement is quite good, especially considering that there was no normalization of spectra.

Below $100 \mathrm{keV}$, the manufacturer-supplied calibration values uniformly overestimate the value of the neutron fluence. It should be noted that the low-energy portion of the spectrum is largely due to wall scattering, and that NIST calibrations using these fields usually employ analytic and empirical corrections to remove the effects of wall scattering. Thus, the low-energy calibration.

Because of the lack of agreement between ROSPEC and calculated spectra, the NIST thermal neutron calibration facility was used to check the low-energy calibration. Only the sensitivity of the bare ${ }^{3} \mathrm{He}$ detector could be measured in this facility. The sensitivity of the boron-covered detector could not be directly measured in the thermal neutron beam because boron, by design, shields the sensitive volume from thermal neutrons. The response of the boron-covered detector was determined by calculation of its sensitivity from known gas pressure and from boron attenuation. The relative response of the boron-covered versus bare ${ }^{3} \mathrm{He}$ detectors as a function of energy was supplied by Bubble Technologies. Calibration results are given in Table 2. 


\section{${ }^{3}$ He Recalibration}

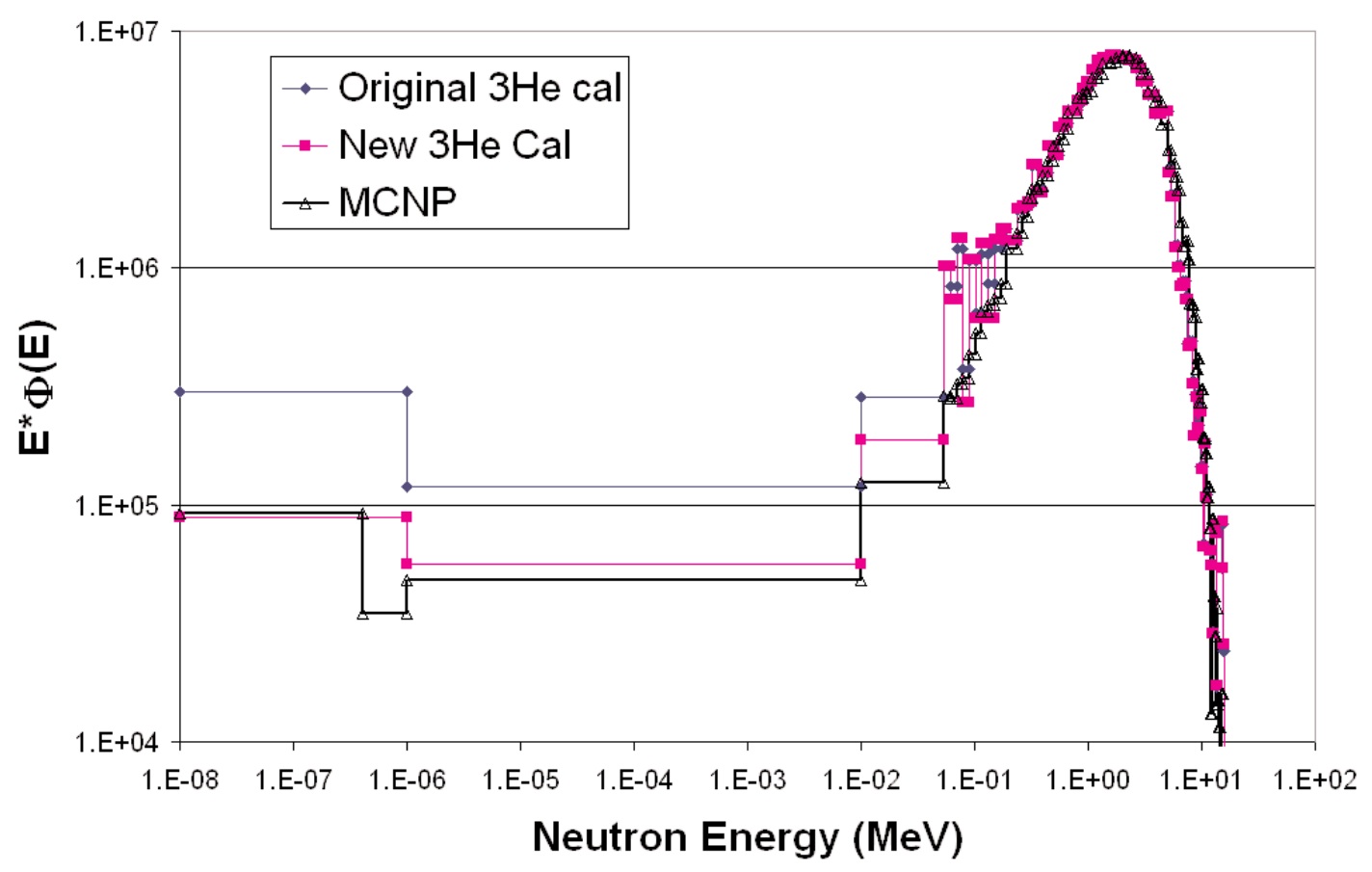

Fig. 4. Bare ${ }^{252} \mathrm{Cf}$ neutron spectrum, calculated and measurements with different calibration factors.

\section{$\mathrm{D}_{2} \mathrm{O}$ Moderated $\mathrm{Cf}$}

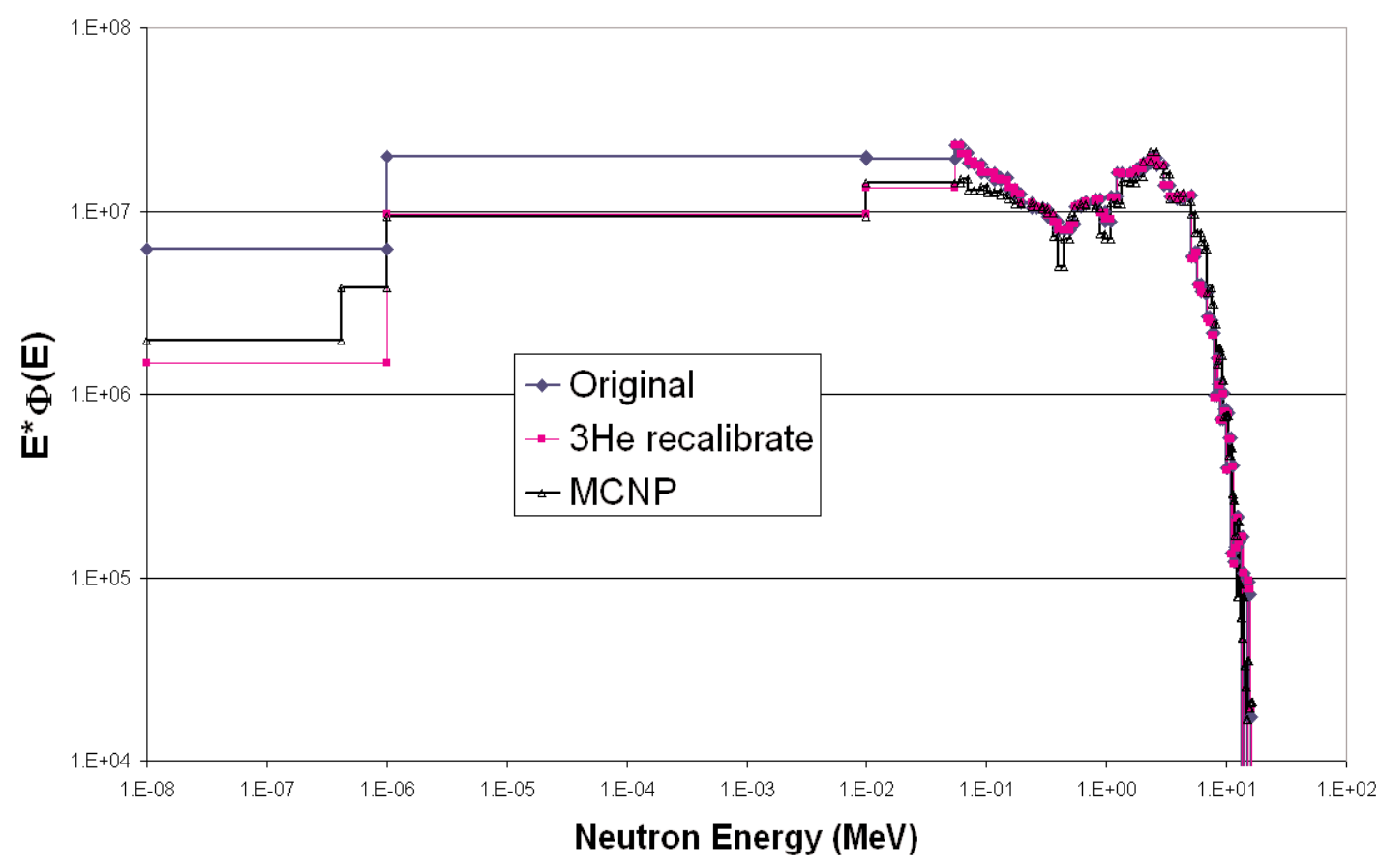

Fig. 5. $\mathrm{D}_{2} \mathrm{O}$-moderated ${ }^{252} \mathrm{Cf}$ neutron spectrum, calculated and measurements with different calibration factors. 
Table 2. Calibration constants

\begin{tabular}{lcc}
\hline Detector & $\begin{array}{c}\text { Manufacturer Neutron } \\
\text { Sensitivity }\end{array}$ & $\begin{array}{c}\text { NIST Neutron } \\
\text { Sensitivity }\end{array}$ \\
\hline Bare ${ }^{3} \mathrm{He}$ & 0.178 & 0.586 \\
Boron-covered ${ }^{3} \mathrm{He}$ & 0.00299 & 0.00583 \\
\hline
\end{tabular}

The unfolding program used by ROSPEC uses net counts above a threshold to determine ${ }^{3} \mathrm{He}$ counts (Fig. 6). It also has a scaling factor to account for neutrons which give counts below the threshold. To avoid confusion with these factors, the calibration technique used here was to insert the ${ }^{3} \mathrm{He}$ counter into a known thermal neutron field and to adjust the ROSPEC calibration factor for the bare ${ }^{3} \mathrm{He}$ counter until the correct unfolded thermal neutron fluence was obtained. The differences between calibration factors supplied with ROSPEC and those obtained here are substantial.
The new factors determined in the NIST thermal neutron facility give a much better fit to the measured Californium spectra, as shown in Figures 4 and 5.

The National Physical Laboratory (NPL) in the United Kingdom had a similar experience with a ROSPEC they evaluated and used similar procedures to obtain their slow-neutron calibration factors [11].

ROSPEC was used to measure $2.5 \mathrm{MeV}$ (deuteriumdeuterium) and $14 \mathrm{MeV}$ (deuterium-tritium) neutrons. As stated above, only the energies and not the intensities of the fields were known. The measured spectra are shown in Figs. 7 and 8. $2.5 \mathrm{MeV}$ is in the region measured by gaseous proton-recoil detectors, and $14 \mathrm{MeV}$ is in the region measured by the plastic scintillator (SSS).

In addition to verifying that ROSPEC can measure $2.5 \mathrm{MeV}$ and $14 \mathrm{MeV}$ neutrons at the correct energies, the measured spectra also indicate the extent to which room scattering contributes to the overall fluence. More is given on this in the next section.

\section{He- 3 counts}

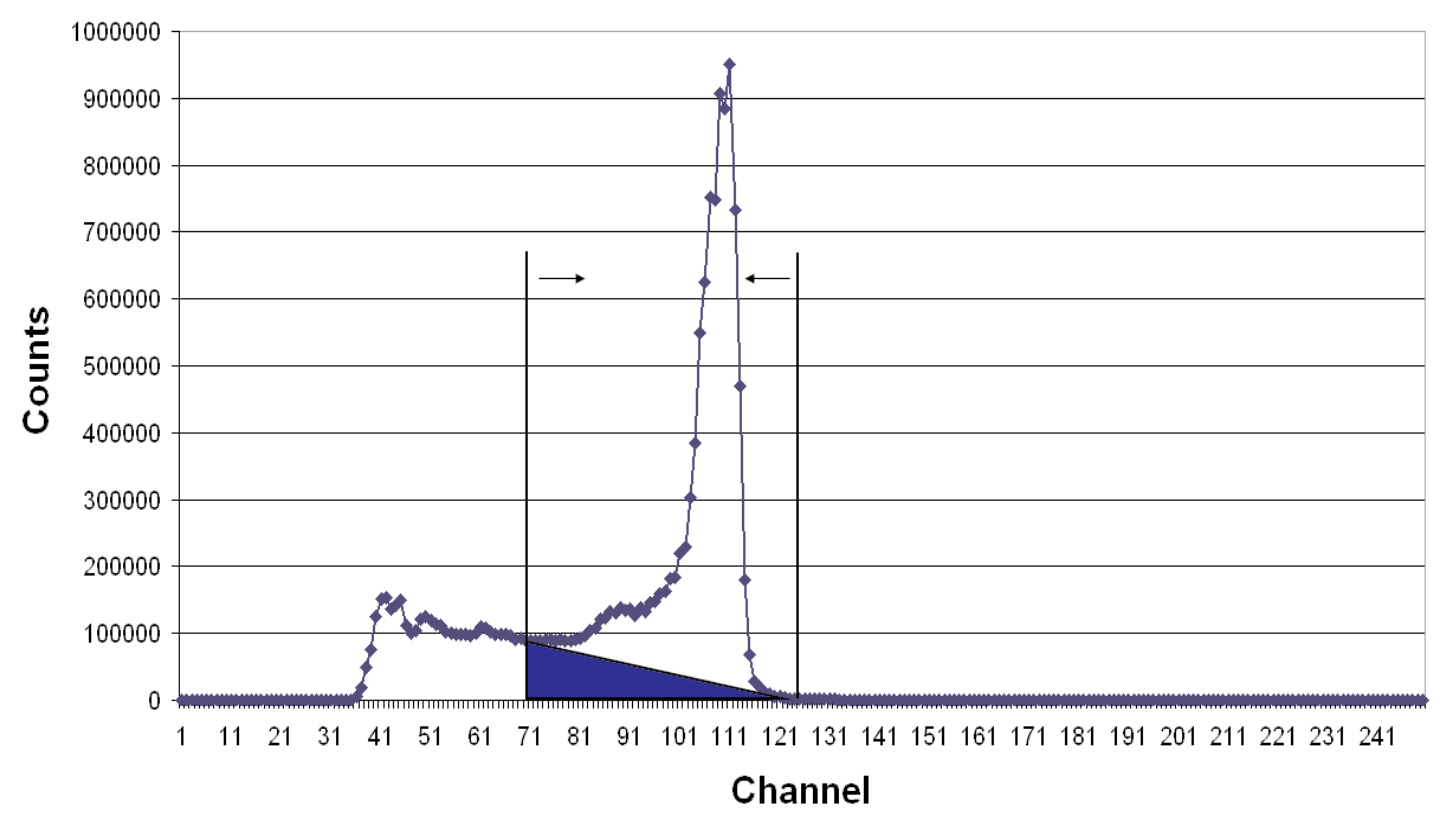

Fig. 6. Measured ${ }^{3} \mathrm{He}$ spectrum. Counts used are net counts above background between two channels. 


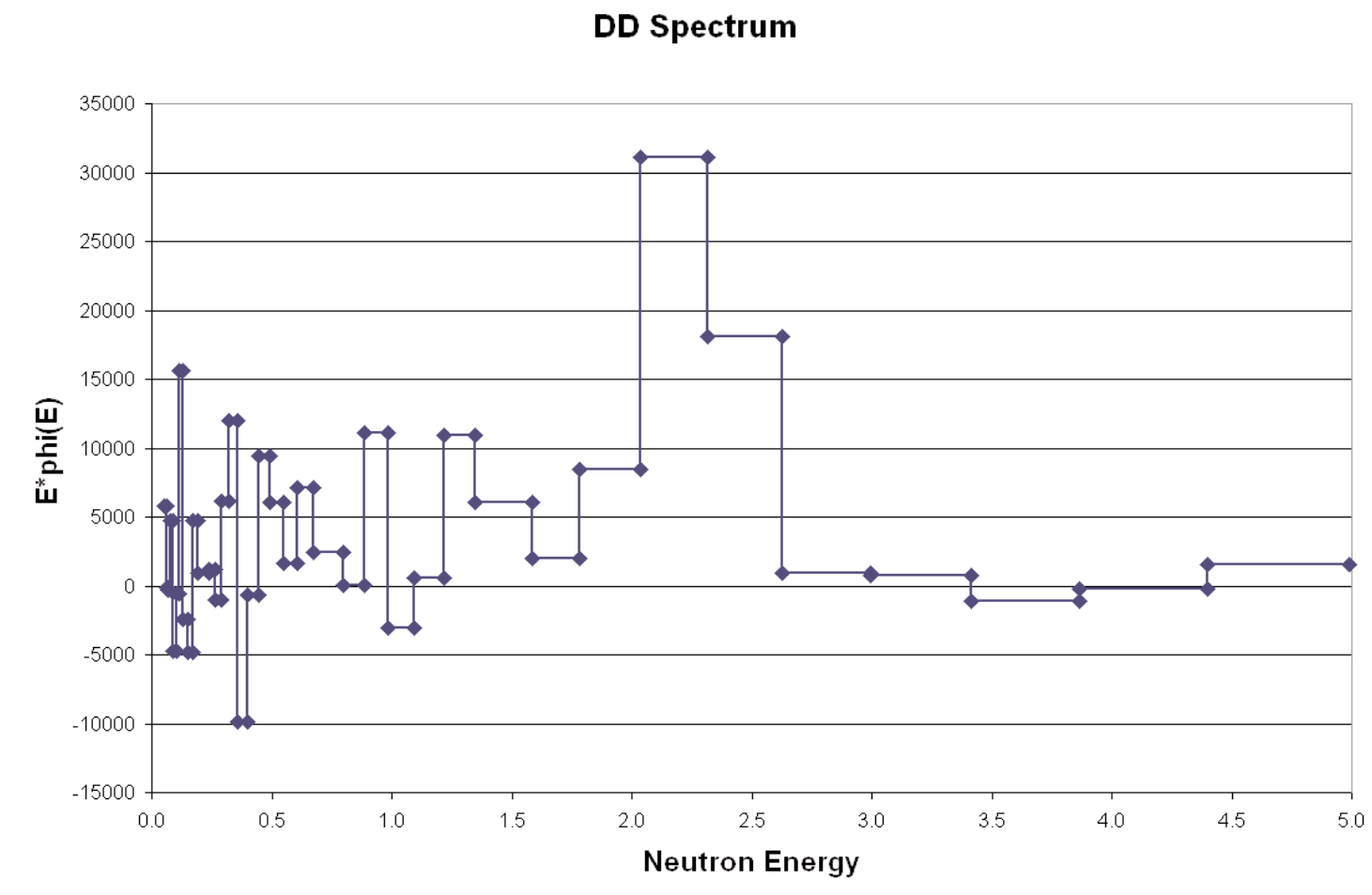

Fig. 7. Measured DD spectrum.

\section{$14 \mathrm{MeV}$}

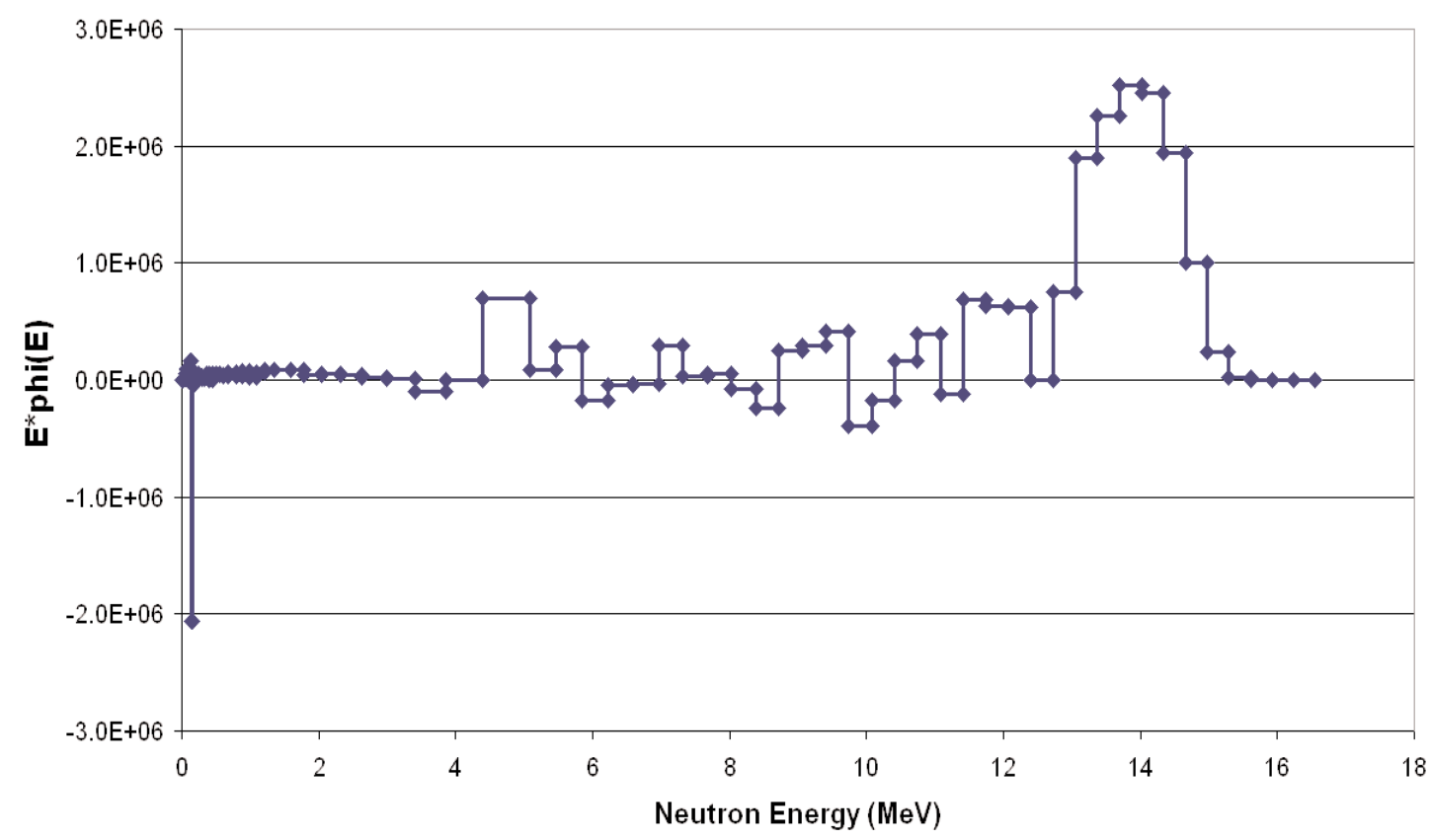

Fig. 8. Measured DT spectrum. 


\section{AmBe Neutron Source}

ROSPEC was used to measure the neutron spectrum of an AmBe neutron source. This source was chosen because such sources are commonly found in commerce and might be confused with illegitimate neutron emitters. These sources are used, among other things, in moisture density gauges.

The neutron spectrum was measured in the NIST Californium Neutron Irradiation Facility. A drawing of the facility is given in Fig. 9. The measured and calculated spectra are shown in Figs. 10 and 11. The uncollided neutron spectrum used for calculation is taken from Ref. [12]. Actual AmBe spectra show substantial variation [13] so that the calculated spectrum used may not be a good representation of the true spectrum.

The calculated spectra show substantial scattering as the source/detector distance increases. The measured spectra show the same trend, with good overall agreement.

The ability to measure neutron spectra in this detail is a capability which ROSPEC brings to NIST.

\section{Comparison of Integral Results}

The number of measured neutrons is compared to the calibration numbers in Table 3. The calculated (no walls) column gives the calculated neutron fluence at the detector location divided by the neutron fluence from an unshielded source. For these calculations, the walls were taken to be vacuum. The units $n / S_{n}$ indicate the number of neutrons $/ \mathrm{cm}^{2}$ at the measurement location, multiplied by $4 \pi \mathrm{r}^{2}$, divided by the number of source neutrons. This normalization gives unity in an unscattered, unattenuated environment and is useful for comparisons.

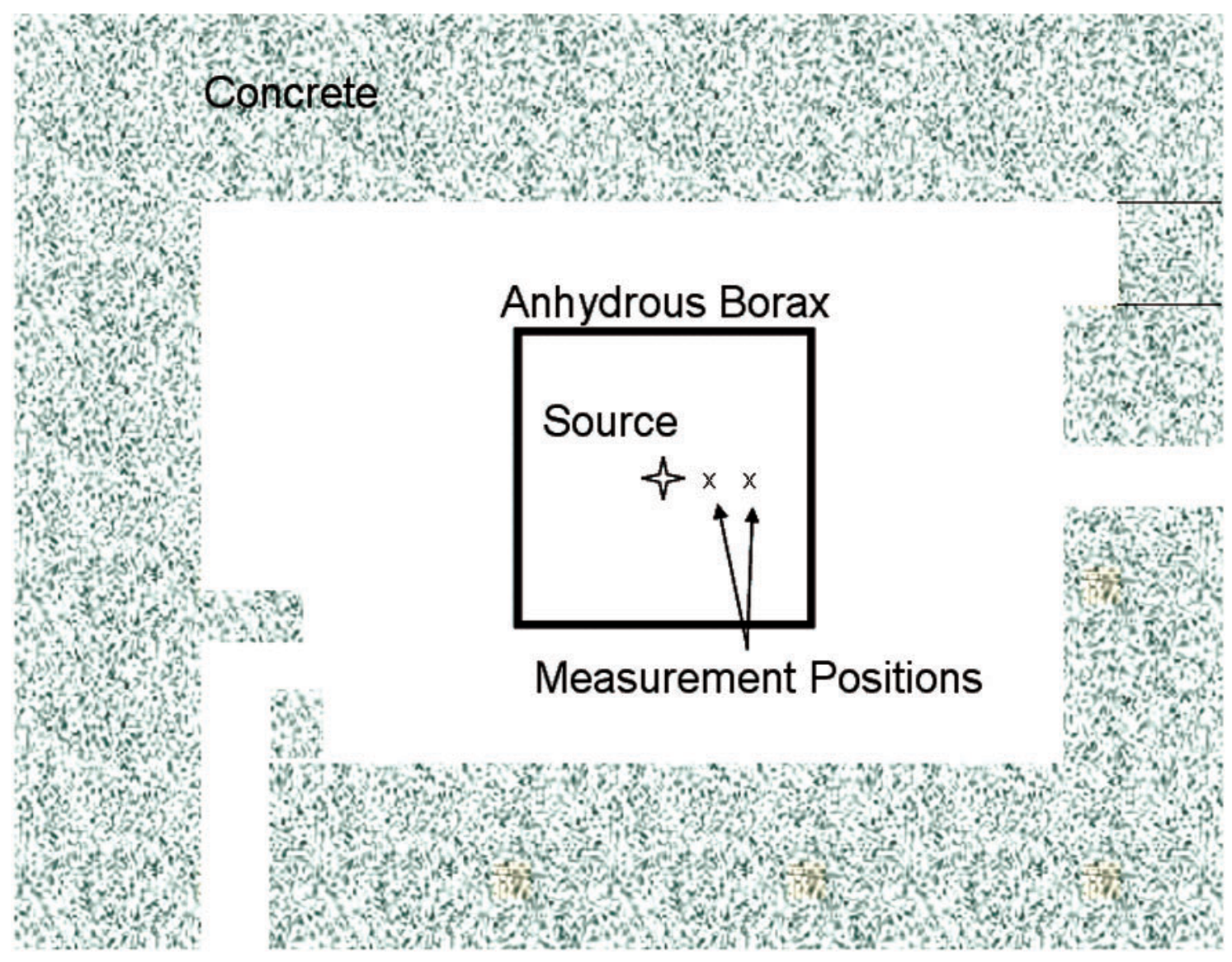

Fig. 9. Californium Nautron Irradiation Facility (CNIF). 


\section{AmBe Neutron Spectrum}

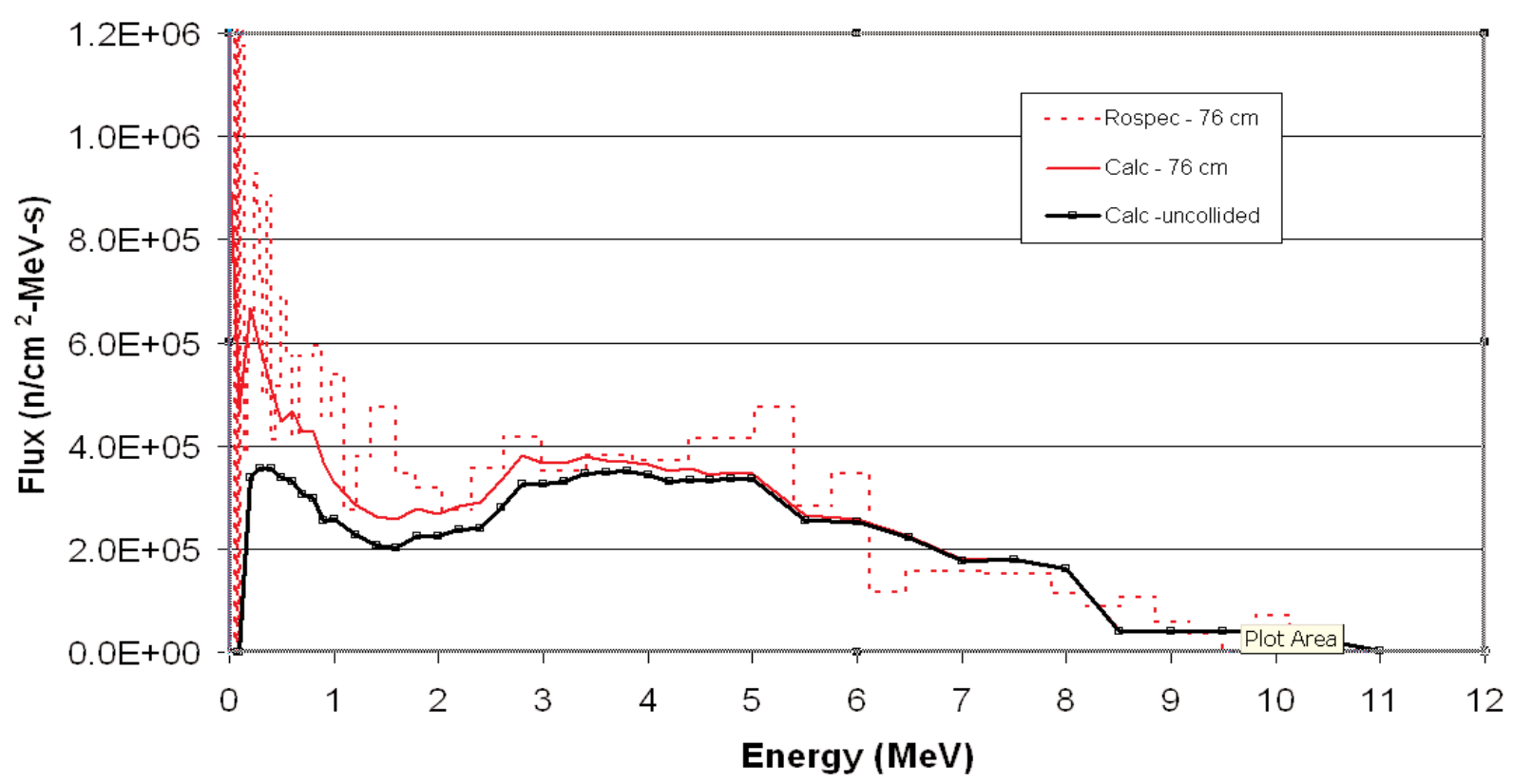

Fig. 10. Measured and calculated AmBe spectra, $76 \mathrm{~cm}$.

\section{AmBe Neutron Spectrum}

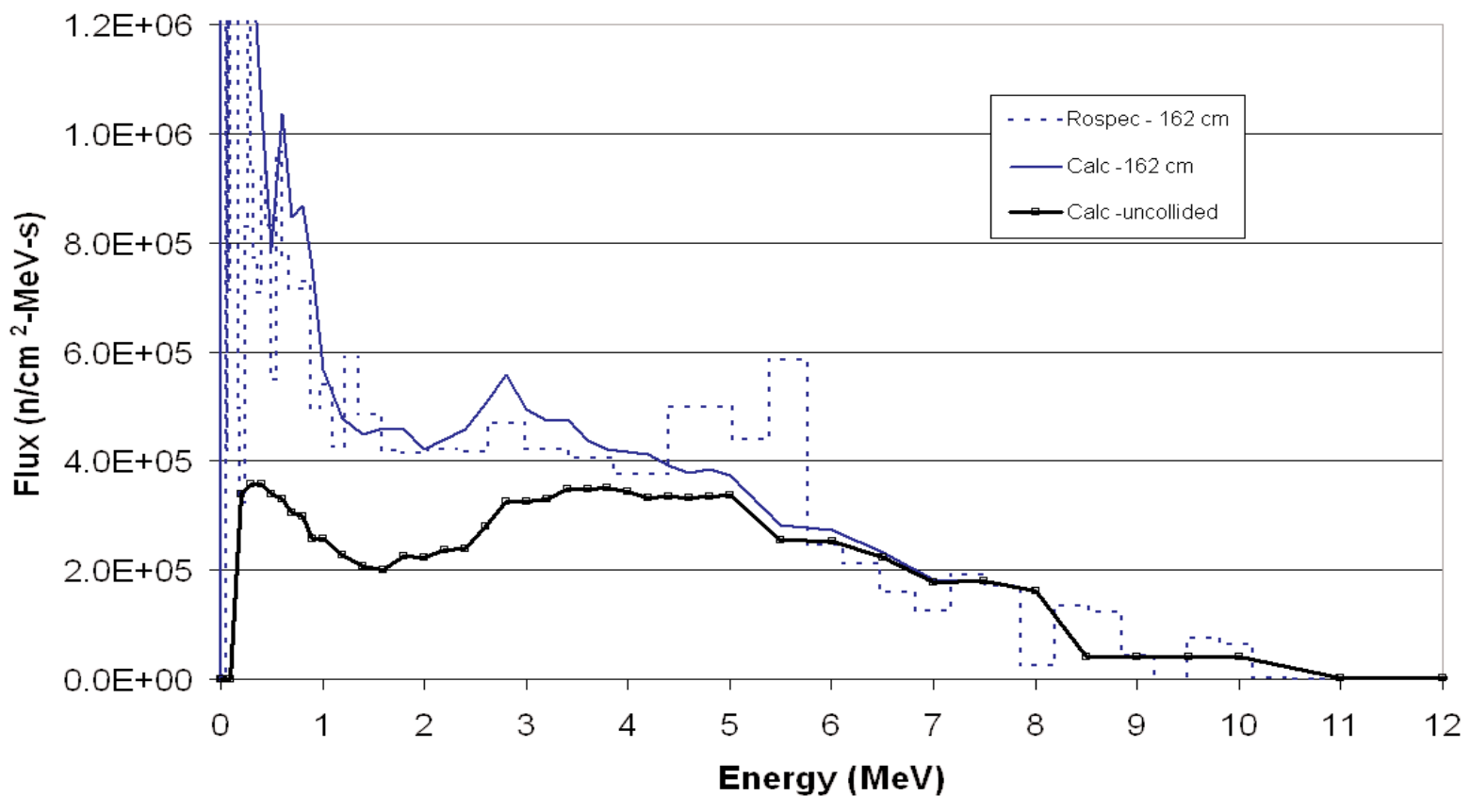

Fig. 11. Measured and calculated AmBe spectra, $162 \mathrm{~cm}$. 
Table 3. Measured and calculated neutron fluences

\begin{tabular}{|c|c|c|c|c|}
\hline Field & $\begin{array}{c}\text { Calculated } \\
\text { No walls } \\
\left(\mathrm{n} / \mathrm{S}_{\mathrm{n}}\right)\end{array}$ & $\begin{array}{c}\text { Calculated } \\
\text { Full Geometry } \\
\left(\mathrm{n} / \mathrm{S}_{\mathrm{n}}\right)\end{array}$ & $\begin{array}{l}\text { Measured } \\
\qquad\left(\mathrm{n} / \mathrm{S}_{\mathrm{n}}\right)\end{array}$ & $\begin{array}{c}\text { Ratio } \\
\text { (Measured / Calculated) } \\
\text { (Full Geometry) }\end{array}$ \\
\hline $\begin{array}{l}\text { Bare }{ }^{252} \mathrm{Cf} \\
(100 \mathrm{~cm})\end{array}$ & 1.00 & 1.12 & 1.19 & 1.06 \\
\hline $\begin{array}{l}\mathrm{D}_{2} \mathrm{O} \text { Moderated } \\
{ }^{252} \mathrm{Cf}(100 \mathrm{~cm})\end{array}$ & 0.91 & 1.05 & 1.05 & 1.00 \\
\hline $\begin{array}{l}\mathrm{AmBe} \\
(76 / 162 \mathrm{~cm})\end{array}$ & 1.00 & $1.15 / 1.67$ & $1.36 / 1.50$ & 1.05 \\
\hline
\end{tabular}

For the bare ${ }^{252} \mathrm{Cf}$ source and the $\mathrm{AmBe}$ source, there is only a point neutron source in the no-walls geometry. For the $\mathrm{D}_{2} \mathrm{O}$ source, the 0.91 results from neutron attenuation and scattering in the $\mathrm{D}_{2} \mathrm{O}$ sphere. The full-geometry column includes scattering from the walls, etc. These numbers are greater than unity because they include both the direct and the scattered neutron fluence.

Agreement between measured and calculated results is good in all cases. The AmBe ratio is an average of ratios made at two distances, a ratio of 1.18 at $76 \mathrm{~cm}$ and ratio of 0.90 at $162 \mathrm{~cm}$.

\section{Summary}

ROSPEC is a useful monitor for neutron fields. It gives a complete measurement of the neutron spectrum from thermal neutron energy up to $17 \mathrm{MeV}$. Since the measured results are not dependent upon fundamental physical parameters, ROSPEC is not suitable for the calibration of standard or reference neutron fields. However, it does verify the neutron spectrum for NIST calibration sources in various geometries, gives a measurement of scattering effects, and can be used to correlate neutron environments encountered in the field against standard or reference environments.

\section{References}

[1] H. Ing, T. Clifford, T. McLean, W. Webb, T. Cousins, and J. Dhermain, ROSPEC-A Simple Reliable High Resolution Neutron Spectrometer, Radiation Protection Dosimetry 70, Nos. 1-4, 273-278 (1997).

[2] P. W. Benjamin, C. D. Kemshall, and A. Brickstock, The Analysis of Recoil Proton Spectra, AWRE 09/68.

[3] J. A. Grundl and C. M. Eisenhauer, Compendium of Benchmark Neutron Fields for Reactor Dosimetry, Natl. Bur. Stand. (U.S.), NBSIR 85-3151 (Apr. 1985).
[4] R. B. Schwartz and C. M. Eisenhauer, The Design and Construction of a $\mathrm{D}_{2} \mathrm{O}-$ Moderated ${ }^{252} \mathrm{Cf}$ Source for Calibrating Neutron Personnel Dosimeters Used at Nuclear Power Reactors, U.S. Nucl. Reg. Com. Doc. NUREG/CR-1204 (Jan. 1980).

[5] R. B. Schwartz, NBS Measurement Services: Neutron Personnel Dosimetry, Natl. Bur. Stand. (U.S.), Spec. Publ. 25012 (July 1987).

[6] R. S. Clement, C. R. Heimbach, and A. K. Thompson, Monte Carlo Calculations of the NIST Heavy-Water-Moderated Cf-252 Sphere. 51st Annual Meeting of the Health Physics Society, Providence, RI (June 25-29, 2006).

[7] MCNP-A General Monte Carlo N-Particle Transport Code, X-5 Monte Carlo Team, LA-UR-03-1987 (2003).

[8] R. B. Schwartz and C. M., Eisenhauer, Test of a Neutron Spectrometer in NIST Standard Fields, Radiation Protection Dosimetry 55, No 2., 99-105 (1994)

[9] W. Rosenstock, T. Köble, G. Kruziniski, and G. Jaunich, Calibration of a Neutron Spectrometer in the Energy Range $144 \mathrm{keV}$ to $14.8 \mathrm{MeV}$ with ISO Energies, Radiation Protection Dosimetry 70, Nos 1-4, pp. 290-303 (1997)

[10] P. Crovisier, B. Asselineau, G. Pelcot, L. Van-Ryckeghem, A. Cadiou, H. Truffert, J. E. Groetz, and M. Benmosbah, French Comparison Exercise with the Rotating Neutron Spectrometer, "ROSPEC" Radiation Protection Dosimetry 115, No 1-4, 324$328(2005)$

[11] D. Thomas, A. Bennett, S. Cheema, N. Hawkes, N. Horwood, L. Jones, P. Kolkowski, N. Roberts, and G. Taylor, Recent Developments in Neutron Metrology ay the National Physical Laboratory, CCRI(III)/05-08 (2005)

[12] Compendium of Neutron Spectra and Detector Responses for Radiation Protection Purposes, IAEA Technical Reports Series No. 403, 2001.

[13] Neutron Fluence, Neutron Spectra and Kerma, ICRU Report 13, 1969.

About the author: C. R. Heimbach is a physicist in the Ionizing Radiation Division at NIST. 